\title{
Expression of $E C R G 4$ is an independent prognostic factor for poor survival in patients with esophageal squamous cell carcinoma
}

\author{
YOICHIRO MORI, HIDEYUKI ISHIGURO, YOSHIYUKI KUWABARA, MASAHIRO KIMURA, \\ AKIRA MITSUI, HIROKI KUREHARA, RYOTA MORI, KEISUKE TOMODA, RYO OGAWA, \\ TAKEYASU KATADA, KOSHIRO HARATA and YOSHITAKA FUJII
}

Nagoya City University Graduate School of Medical Sciences, Oncology, Immunology and Surgery, 1 Kawasumi, Mizuho-cho, Mizuho-ku, Nagoya 467-8601, Japan

Received March 5, 2007; Accepted June 7, 2007

\begin{abstract}
In this study, we examined the expression of esophageal cancer-related gene 4 (ECRG4) mRNA and evaluated its clinical significance in esophageal squamous cell carcinoma (ESCC). ECRG4 mRNA expression was quantified by real-time RT-PCR in 63 ESCC and corresponding normal esophageal mucosal samples. ECRG4 mRNA expression levels were significantly lower in ESCC tissues compared with corresponding normal esophageal mucosa $(\mathrm{P}<0.0001)$, in patients with locally invasive T2-4 tumors compared with less invasive $\mathrm{T} 1$ tumors $(\mathrm{P}=0.0229)$ and in stage 4 tumors compared with stage $0-3$ tumors $(\mathrm{P}=0.0120)$. Furthermore, low ECRG4 mRNA expression levels were associated with significantly shorter survival after surgery compared with high ECRG4 mRNA expression levels $(\mathrm{P}=0.0150)$ in ESCC patients. On the basis of multivariate analysis, we conclude that ECRG4 mRNA expression level could be a candidate for an independent prognostic factor for ESCC patients.
\end{abstract}

\section{Introduction}

In Japan, esophageal squamous cell carcinoma (ESCC) is the ninth most frequent cancer. However, it is the sixth most frequent cause of death from malignant tumors, and the number of deaths due to this cancer has been steadily increasing. ESCC is often diagnosed at an advanced stage and the prognosis remains poor, prompting the search for new treatment strategies. Although pre-operative chemotherapy and chemoradiation therapy are currently used for patients with advanced-stage ESCC, their results are unsatisfactory.

Correspondence to: Dr Hideyuki Ishiguro, Nagoya City University Graduate School of Medical Sciences, Oncology, Immunology and Surgery, 1 Kawasumi, Mizuho-cho, Mizuho-ku, Nagoya 467-8601, Japan

E-mail: h-ishi@med.nagoya-cu.ac.jp

Key words: esophageal cancer-related gene 4, quantitative RT-PCR, esophageal squamous cell carcinoma
Even among patients with early-stage disease, we have observed many who develop locally recurrent tumors or distant metastases within a short period after curative surgery. Molecular biological studies have revealed that ESCC is caused by the accumulation of multiple genetic changes in oncogenes and tumor suppressor genes.

The esophageal cancer-related gene 4 (ECRG4), a novel tumor suppressor gene candidate, was cloned and identified by $\mathrm{Su}$ et al from normal human esophageal epithelium in 1998 (1). Its function is unknown and its role in ESCC has not been studied. In this study, we investigated the ECRG4 mRNA expression in ESCC and in its paired normal esophageal mucosa by real-time RT-PCR using a LightCycler system. We analysed the results with reference to the clinicopathological characteristics and the prognosis of the ESCC patients.

\section{Materials and methods}

Tissue samples. Tissue samples were obtained from 63 patients with primary ESCC who had undergone radical esophagectomy at the Department of Surgery II, Nagoya City University Medical School, between 1996 and 2001. The study design was approved by the Institutional Review Board of our university hospital, and a written consent was obtained from each patient. The tumors were classified according to the Guidelines for the Clinical and Pathological Studies on Carcinoma of the Esophagus. The patients comprised of 50

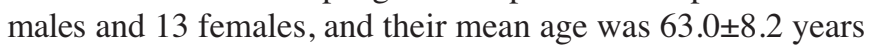
(range, 46-79 years). All the samples were frozen immediately in liquid nitrogen and stored at $-80^{\circ} \mathrm{C}$ until use. The clinicopathological factors and the tumor and patient characteristics of the 63 subjects are shown in Table I.

RNA extraction and RT-PCR analysis. Total RNA was extracted from ESCC tissue and from corresponding normal esophageal mucosa taken from apparently non-cancerous mucosa as far away from the tumor as possible, using the Isogen kit (Nippon Gene, Tokyo, Japan) according to the manufacturer's instructions. The concentration of total RNA was adjusted to $200 \mathrm{ng} / \mathrm{ml}$ with a spectrophotometer. The reverse transcription reaction was carried out at $42^{\circ} \mathrm{C}$ for 
Table I. Correlation of ECRG4 mRNA expression in esophageal cancer with clinicopathological factors, including patient and tumor characteristics.

\begin{tabular}{|c|c|c|c|}
\hline Characteristics & $\begin{array}{l}\text { No. of patients } \\
\quad(n=63)\end{array}$ & $\begin{array}{l}E C R G 4 \text { expression } \\
\text { relative to GAPDH }\end{array}$ & P-value \\
\hline Normal & 63 & $176.5 \pm 271.4$ & \\
\hline Tumor & 63 & $85.4 \pm 167.1$ & $<0.0001$ \\
\hline \multicolumn{4}{|l|}{ Age at surgery } \\
\hline$<65$ years & 36 & $95.2 \pm 194.6$ & \\
\hline$\geq 65$ years & 27 & $72.3 \pm 123.9$ & 0.8350 \\
\hline \multicolumn{4}{|l|}{ Gender } \\
\hline Male & 50 & $88.6 \pm 177.1$ & \\
\hline Female & 13 & $73.1 \pm 126.8$ & 0.7341 \\
\hline \multicolumn{4}{|l|}{ Tumor status } \\
\hline $\mathrm{T} 1$ & 10 & $151.1 \pm 281.1$ & \\
\hline $\mathrm{T} 2$ & 6 & $72.4 \pm 107.4$ & \\
\hline $\mathrm{T} 3$ & 32 & $95.5 \pm 163.1$ & \\
\hline $\mathrm{T} 4$ & 15 & $25.3 \pm 51.5$ & 0.0651 \\
\hline \multicolumn{4}{|c|}{ Lymph node status } \\
\hline No & 12 & $70.0 \pm 122.6$ & \\
\hline N1 & 11 & $64.9 \pm 94.2$ & \\
\hline $\mathrm{N} 2$ & 22 & $93.1 \pm 213.0$ & \\
\hline N3 & 9 & $166.9 \pm 221.0$ & \\
\hline N4 & 7 & $39.1 \pm 78.5$ & 0.1728 \\
\hline Unknown & 2 & & \\
\hline \multicolumn{4}{|c|}{ Pathological stage } \\
\hline 0 & 3 & $41.7 \pm 6.7$ & \\
\hline I & 3 & $53.3 \pm 47.3$ & \\
\hline II & 11 & $138.2 \pm 275.2$ & \\
\hline III & 23 & $126.9 \pm 183.5$ & \\
\hline IV & 23 & $28.6 \pm 58.7$ & 0.1432 \\
\hline \multicolumn{4}{|l|}{ Histological } \\
\hline \multicolumn{4}{|l|}{ differentiation } \\
\hline Well & 21 & $113.9 \pm 217.8$ & \\
\hline Moderate & 31 & $77.0 \pm 151.7$ & \\
\hline Poor & 7 & $40.9 \pm 32.0$ & 0.3639 \\
\hline Unknown & 4 & & \\
\hline \multicolumn{4}{|c|}{ Lymphatic invasion } \\
\hline Negative & 12 & $133.7 \pm 262.5$ & \\
\hline Positive & 39 & $76.2 \pm 147.2$ & 0.3070 \\
\hline Unknown & 12 & & \\
\hline \multicolumn{4}{|c|}{ Blood vessel invasion } \\
\hline Negative & 21 & $109.1 \pm 214.0$ & \\
\hline Positive & 30 & $76.1 \pm 153.4$ & 0.2065 \\
\hline Unknown & 12 & & \\
\hline
\end{tabular}

${ }^{\mathrm{a}}$ Mean \pm standard deviation (SD). ECRG4, esophageal cancer-related gene 4; GAPDH, glyceraldehyde-3-phosphate dehydrogenase.

90 min and $95^{\circ} \mathrm{C}$ for $5 \mathrm{~min}$, followed by incubation at $72^{\circ} \mathrm{C}$ for $15 \mathrm{~min}$, using $1 \mu \mathrm{g}$ of total RNA and $0.5 \mu \mathrm{g}$ each of oligo(dT) primer and Superscript II enzyme (Gibco BRL, Gaithersburg, MD). All the samples were quantified after

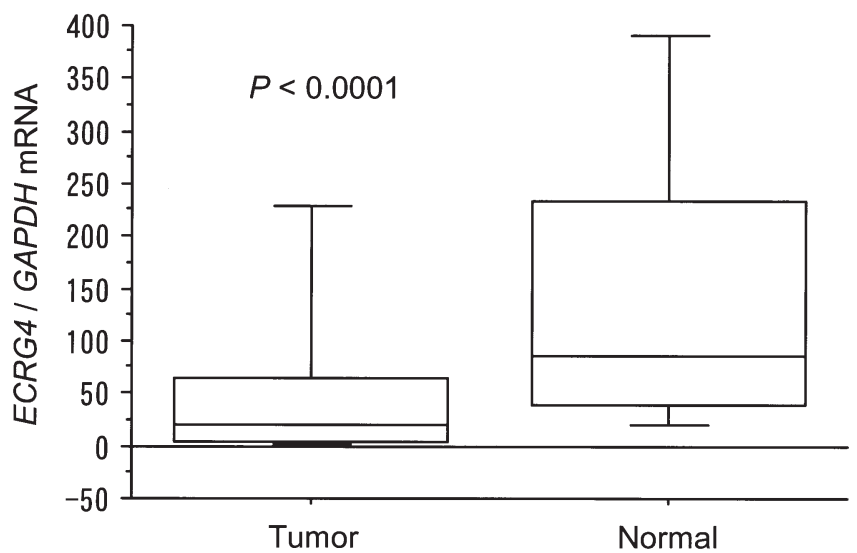

Figure 1. ECRG4/GAPDH mRNA expression levels in ESCC tissue were significantly lower than those in the corresponding normal esophageal mucosal tissue $(85.4 \pm 167.1$ vs. $176.5 \pm 271.4, \mathrm{P}<0.0001$; Wilcoxon signedranks test).

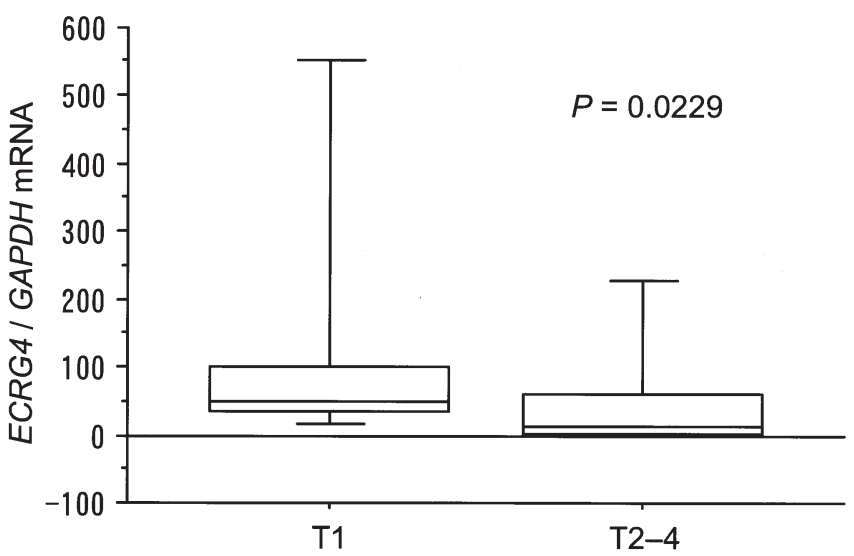

Figure 2. ECRG4/GAPDH mRNA expression levels in patients with locally invasive T2-4 tumors were significantly lower than those in less invasive T1 tumors ( $\mathrm{P}=0.0229$, Mann-Whitney U test).

PCR amplification using a Lightcycler-Faststart DNA Master SYBR-Green I kit (Roche Molecular Biochemicals, Mannheim, Germany). We used the following set of primers: forward primer ECRG4-F, 5'-AAGTGGCCGTTGATGAG AAT-3'; and reverse primer ECRG4-R, 5'-GGGACCAA TTGCAGAGTCTT-3'. The size of the product was $245 \mathrm{bp}$. The PCR protocol was: initial denaturation at $95^{\circ} \mathrm{C}$ for $10 \mathrm{~min}$, followed by 45 cycles at $95^{\circ} \mathrm{C}$ for $10 \mathrm{sec}$, annealing at $60^{\circ} \mathrm{C}$ for $5 \mathrm{sec}$ and extension at $72^{\circ} \mathrm{C}$ for $10 \mathrm{sec}$. The PCR product was quantified on the basis of the intensity of SYBR-Green I at $72^{\circ} \mathrm{C}$.

Statistical analysis. The relative ECRG4 mRNA expression levels were calculated from quantified data in reference to the expression level of the glyceraldehyde-3-phosphate dehydrogenase $(G A P D H)$ gene. The data are expressed as the means \pm standard deviation $(\mathrm{SD})$. Statistical analysis was performed using the software package StatView (Abacus Concepts, Berkeley, CA). The Wilcoxon signed-ranks test, Mann-Whitney U test and Kruskal-Wallis test were used to evaluate the significance of the differences in the expression 


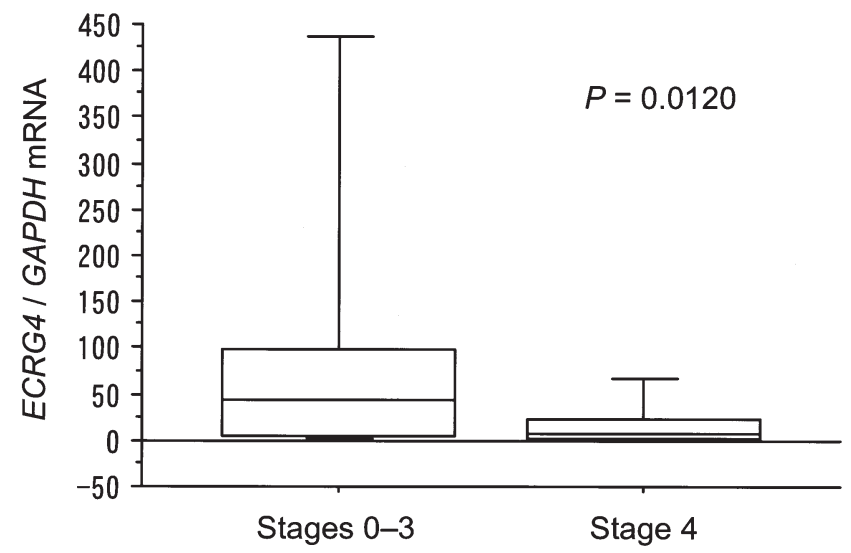

Figure 3. ECRG4/GAPDH mRNA expression levels in patients with histological stage 4 tumors were significantly lower than those in histological stages 0-3 tumors $(\mathrm{P}=0.0120$, Mann-Whitney $\mathrm{U}$ test).

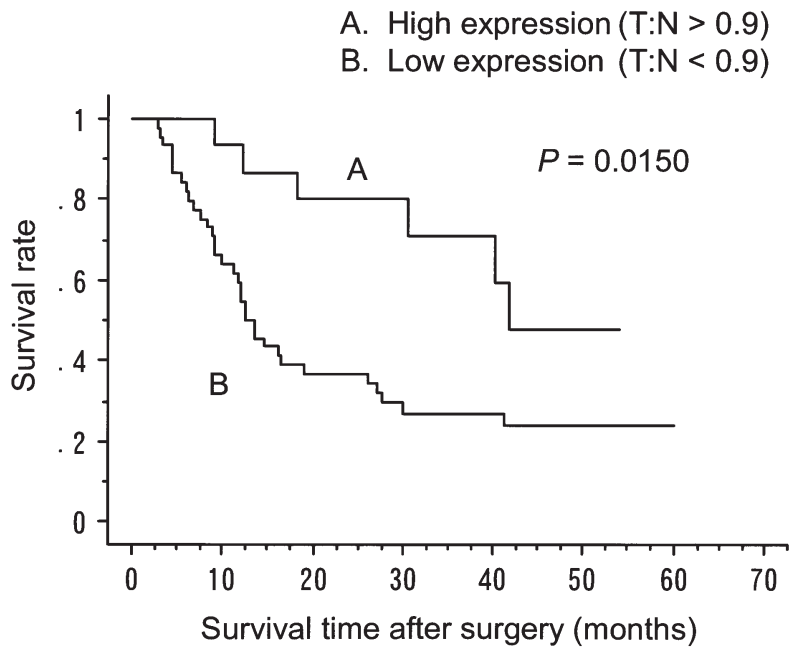

Figure 4. Patients who had low ECRG4/GAPDH mRNA expression levels [indicated as the ratio of ECRG4/GAPDH mRNA expression in the tumor to that in normal esophageal mucosa $(\mathrm{T}: \mathrm{N}$ ratio $)<0.9, \mathrm{n}=47$ ] had a significantly shorter survival (13.0 \pm 2.1 months) after surgery compared with patients who had high ECRG4 mRNA expression levels (T:N ratio $>0.9$, $\mathrm{n}=16 ; 42.0 \pm 2.7$ months $)(\mathrm{P}=0.0150, \log$-rank test $)$.

levels of ECRG4/GAPDH mRNA. The survival of the ESCC patients after surgery was examined using the Kaplan-Meier method, and the survival times were compared using the log-rank test. Multivariate analysis was performed using the Cox regression model and a logistic multivariate regression model. In all analyses, $\mathrm{P}<0.05$ was considered statistically significant.

\section{Results}

ECRG4/GAPDH mRNA expression was detectable in all the samples of ESCC tissue and non-cancerous esophageal mucosal tissue. The respective levels of expression in ESCC tissue were significantly lower than those in the corresponding normal esophageal mucosa $(85.4 \pm 167.1$ vs. $176.5 \pm 271.4$, $\mathrm{P}<0.0001$; Wilcoxon signed-ranks test) (Fig. 1 and Table I). We examined the relationship between ECRG4/GAPDH
Table II. Univariate analysis of the factors that influence the prognosis of ESCC patients.

\begin{tabular}{|c|c|c|c|}
\hline Parameter & Risk ratio & $95 \% \mathrm{CI}$ & P-value \\
\hline \multicolumn{4}{|c|}{ Age at surgery } \\
\hline$<65$ years & 1 & & \\
\hline$\geq 65$ years & 1.669 & $0.871-3.194$ & 0.1129 \\
\hline \multicolumn{4}{|l|}{ Gender } \\
\hline Male & 1 & & \\
\hline Female & 1.080 & $0.509-2.290$ & 0.8381 \\
\hline \multicolumn{4}{|l|}{ Tumor status } \\
\hline $\mathrm{T} 1-3$ & 1 & & \\
\hline $\mathrm{T} 4$ & 4.566 & $2.179-9.523$ & $<0.0001$ \\
\hline \multicolumn{4}{|c|}{ Lymph node status } \\
\hline N0-3 & 1 & & \\
\hline N4 & 3.690 & $1.497-9.090$ & 0.0022 \\
\hline \multicolumn{4}{|c|}{ Lymphatic invasion } \\
\hline Negative & 1 & & \\
\hline Positive & 6.711 & $1.575-28.57$ & 0.0027 \\
\hline \multicolumn{4}{|c|}{ Blood vessel invasion } \\
\hline Negative & 1 & & \\
\hline Positive & 2.793 & $1.199-6.536$ & 0.0123 \\
\hline \multicolumn{4}{|c|}{ ECRG4 expression (T:N) } \\
\hline High & 1 & & \\
\hline Low & 2.801 & $1.163-6.757$ & 0.0150 \\
\hline
\end{tabular}

mRNA expression in 63 ESCC samples and the patients clinicopathological factors (Table I). There were no significant differences in ECRG4/GAPDH mRNA with respect to age, gender, lymph node status, histological differentiation, lymphatic invasion and blood vessel invasion. The ECRG4/GAPDH mRNA expression levels in patients with locally invasive T2-4 tumors were significantly lower than those in the less invasive $\mathrm{T} 1$ tumors $(\mathrm{P}=0.0229$, Mann-Whitney U test) (Fig. 2). The ECRG4/GAPDH mRNA expression levels in patients with stage 4 tumors were significantly lower than those in the tumors in stages 0-3 ( $\mathrm{P}=0.0120$, Mann-Whitney U test) (Fig. 3).

We investigated the correlation between the ECRG4/ GAPDH mRNA expression levels and the survival of ESCC patients after surgery (median follow-up, 22.8 months). Patients who had low ECRG4/GAPDH mRNA expression levels [indicated as the ratio of ECRG4/GAPDH mRNA expression in the tumor to that in normal esophageal mucosa ( $\mathrm{T}: \mathrm{N}$ ratio) $<0.9, \mathrm{n}=47$ ] had a significantly shorter survival

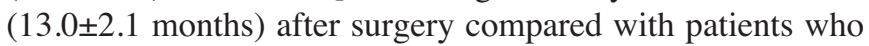
had high ECRG4/GAPDH mRNA expression levels (T:N ratio $>0.9, \mathrm{n}=16 ; 42.0 \pm 2.7$ months $)(\mathrm{P}=0.0150$, log-rank test $)$ (Fig. 4). Univariate analysis revealed that among the clinicopathological factors, the local invasiveness (Tumor status) (risk ratio, 4.566; $\mathrm{P}<0.0001$ ), lymph node metastasis (Node status) (risk ratio, 3.690; $\mathrm{P}=0.0022$ ), lymphatic invasion (risk 
Table III. Multivariate analysis of the factors that influence the prognosis of ESCC patients.

\begin{tabular}{lccc}
\hline Parameter & Risk ratio & $95 \% \mathrm{CI}$ & P-value \\
\hline $\begin{array}{l}\text { Tumor status } \\
\text { T1-3 }\end{array}$ & 1 & & \\
$\quad \mathrm{~T} 4$ & 2.985 & $0.810-10.989$ & 0.1002 \\
Lymph node status & & & \\
$\quad$ N0-3 & 1 & & \\
$\quad$ N4 & 5.208 & $1.013-27.027$ & 0.0482 \\
Lymphatic invasion & & & \\
$\quad$ Negative & 1 & & \\
$\quad$ Positive & 6.849 & $1.256-37.037$ & 0.0262 \\
Blood vessel invasion & & & \\
$\quad$ Negative & 1 & & \\
$\quad$ Positive & 0.971 & $0.344-2.740$ & 0.9549 \\
$\quad$ ECRG4 expression (T:N) & & & \\
$\quad$ High & 1 & & 0.0490 \\
$\quad$ Low & 2.740 & $0.990-7.576$ & \\
\hline
\end{tabular}

CI, confidence interval.

ratio, 6.711; $\mathrm{P}=0.0027$ ), blood vessel invasion (risk ratio, 2.793; $\mathrm{P}=0.0123$ ) and $E C R G 4$ expression (T:N ratio) (risk ratio, $2.801 ; \mathrm{P}=0.0150$ ) were statistically significant prognostic factors (Table II). Multivariate analysis revealed that the extent of lymph node metastasis $(\mathrm{P}=0.0482)$, lymphatic invasion $(\mathrm{P}=0.0262)$ and $E C R G 4$ expression ( $\mathrm{T}: \mathrm{N}$ ratio) $(\mathrm{P}=0.0490)$ were independent prognostic factors (Table III).

\section{Discussion}

We examined ECRG4 mRNA expression in ESCC tissue and the corresponding normal esophageal mucosa. The $E C R G 4$ gene was expressed abundantly in adult esophageal epithelium but was down-regulated in ESCC. This suggests that the ECRG4 gene might be involved in the development of ESCC. This gene is located on chromosome $2 \mathrm{q} 12.2$ and has four exons. The mechanisms that down-regulate ECRG4, including DNA methylation, mutation and loss of heterozygosity (LOH), were not examined in this study. However, $\mathrm{LOH}$ in $2 \mathrm{q}$ has been detected in esophageal cancer in Chinese patients, and this region was suggested to harbour the putative tumor suppressor gene within this region (2).

Many tumor suppressor genes are down-regulated by promoter methylation during the development and progression of cancer, and hypermethylation of gene-promoter regions is being revealed as one of the most frequent mechanisms responsible for the loss of gene function; therefore, the detection of $\mathrm{CpG}$ methylation is an important step in understanding the gene regulation of cancer. It has been reported that the expression of certain tumor suppressor genes, such as p15INK4b, p16INK4a, fragile histidine triad (FHIT) and E-cadherin, are commonly down-regulated by $\mathrm{CpG}$ island hypermethylation in ESCC (3-6). Yue et al reported that aberrant methylation of $\mathrm{CpG}$ islands in the core promoter of the ECRG4 gene was a frequent molecular event in ESCC, and proved for the first time that the loss or lower expression of ECRG4 was associated with ECRG4-CpG island methylation. Further, they found that there were $\mathrm{CpG}$ islands in the promoter region of exon 1 and part of intron 1 of the gene. These results indicate that the inactivation of the $E C R G 4$ gene by hypermethylation may be involved in the carcinogenesis of ESCC (7).

In our study, the ECRG4 mRNA expression levels correlated significantly with the local invasiveness (tumor status), pathological stages and the prognosis of ESCC patients. The patients whose tumors expressed higher levels of ECRG4 mRNA survived longer than those with lower levels of expression. Thus, the down-regulation of ECRG4 may contribute to tumor growth in ESCC.

Moreover, the expression of this gene in the T1 and T2-4 tumors was significantly different. It has been reported that the prognosis of ESCC in patients with T1 tumors who underwent chemoradiation therapy or surgery was similar (8). Therefore, it is increasingly more important to select for surgery only those patients who will benefit from the same. ECRG4 mRNA expression may identify tumors of a more malignant nature despite demonstrating similar clinical stages.

In ESCC patients, many prognostic markers such as cyclin D1, E-cadherin and murine double-minute type 2 (MDM2) have been proposed $(9,10)$. It has also been reported that the expression of survivin (11), DNA fragmentation factor 45 (DFF45) (12), pituitary tumor transforming gene 1 (PTTG1) (13), checkpoint with FHA and ring finger (chfr) (14), peroxisome proliferator activated receptor $\gamma(P P A R \gamma)(15)$, excision repair cross complementing 3 (ERCC3) (16), acid phosphatase 6, lysophosphatidic (ACP6) (17), poly(A) binding protein, cytoplasmic 1 (PABPC1) (18) and N-myc downstream regulated gene 1 (NDRG1) (19) may be prognostic markers of ESCC. ECRG4 has now been added as a possible prognostic indicator in ESCC patients.

Although the precise molecular mechanism of the downregulation of ECRG4 expression needs to be clarified, our data indicate that $E C R G 4$ may be a good molecular prognostic marker for patients with ESCC. Elucidating the function of ECRG4 may lead to a better understanding of the carcinogenic mechanism of tumor progression in patients with ESCC.

\section{Acknowledgements}

We would like to thank Ms. Shinobu Makino for her excellent technical assistance.

\section{References}

1. Su T, Liu H and Lu S: Cloning and identification of cDNA fragments related to human esophageal cancer. Zhonghua Zhong Liu Za Zhi 20: 254-257, 1998.

2. Hu N, Roth MJ, Polymeropolous M, et al: Identification of novel regions of allelic loss from a genomewide scan of esophageal squamous-cell carcinoma in a high-risk Chinese population. Genes Chromosomes Cancer 27: 217-228, 2000.

3. Wong DJ, Barrett MT, Stoger R, Emond MJ and Reid BJ: p16INK4a promoter is hypermethylated at a high frequency in esophageal adenocarcinomas. Cancer Res 57: 2619-2622, 1997. 
4. Tanaka H, Shimada Y, Harada H, Shinoda M, Hatooka S, Imamura $M$ and Ishizaki $\mathrm{K}$ : Methylation of the 5' $\mathrm{CpG}$ island of the FHIT gene is closely associated with transcriptional inactivation in esophageal squamous cell carcinomas. Cancer Res 58: 3429-3434, 1998.

5. Xing EP, Nie Y, Song Y, Yang GY, Cai YC, Wang LD and Yang CS: Mechanisms of inactivation of p14ARF, p15INK4b, and p16INK4a genes in human esophageal squamous cell carcinoma. Clin Cancer Res 5: 2704-2713, 1999.

6. Si HX, Tsao SW, Lam KY, et al: E-cadherin expression is commonly downregulated by $\mathrm{CpG}$ island hypermethylation in esophageal carcinoma cells. Cancer Lett 173: 71-78, 2001.

7. Yue CM, Deng DJ, Bi MX, Guo LP and Lu SH: Expression of ECRG4, a novel esophageal cancer-related gene, downregulated by $\mathrm{CpG}$ island hypermethylation in human esophageal squamous cell carcinoma. World J Gastroenterol 9: 1174-1178, 2003.

8. Okawa T, Tanaka M, Kita M, et al: Radiotherapy for superficial esophageal cancer. Int J Radiat Oncol Biol Phys 30: 959-964, 1994.

9. Shimada Y, Imamura M, Shibagaki I, Tanaka H, Miyahara T, Kato $\mathrm{M}$ and Ishizaki K: Genetic alterations in patients with esophageal cancer with short- and long-term survival rates after curative esophagectomy. Ann Surg 226: 162-168, 1997.

10. Japanese Society for Esophageal Diseases: Prognostic significance of CyclinD1 and E-Cadherin in patients with esophageal squamous cell carcinoma: multi-institutional retrospective analysis. Research Committee on Malignancy of Esophageal Cancer. J Am Coll Surg 192: 708-718, 2001.

11. Kato J, Kuwabara Y, Mitani M, et al: Expression of survivin in esophageal cancer: correlation with the prognosis and response to chemotherapy. Int J Cancer 95: 92-95, 2001.
12. Konishi S, Ishiguro H, Shibata Y, et al: Decreased expression of DFF45/ICAD is correlated with a poor prognosis in patients with esophageal carcinoma. Cancer 95: 2473-2478, 2002.

13. Shibata Y, Haruki N, Kuwabara Y, et al: Expression of PTTG (pituitary tumor transforming gene) in esophageal cancer. Jpn J Clin Oncol 32: 233-237, 2002.

14. Shibata Y, Haruki N, Kuwabara Y, et al: Chfr expression is downregulated by $\mathrm{CpG}$ island hypermethylation in esophageal cancer. Carcinogenesis 23: 1695-1699, 2002.

15. Terashita Y, Sasaki H, Haruki N, et al: Decreased peroxisome proliferator-activated receptor gamma gene expression is correlated with poor prognosis in patients with esophageal cancer. Jpn J Clin Oncol 32: 238-243, 2002.

16. Terashita $\mathrm{Y}$, Ishiguro $\mathrm{H}$, Haruki $\mathrm{N}$, et al: Excision repair cross complementing 3 expression is involved in patient prognosis and tumor progression in esophageal cancer. Oncol Rep 12: 827-831, 2004.

17. Ando T, Ishiguro H, Kuwabara Y, et al: Expression of ACP6 is an independent prognostic factor for poor survival in patients with esophageal squamous cell carcinoma. Oncol Rep 15: 1551-1555, 2006.

18. Takashima N, Ishiguro H, Kuwabara $\mathrm{Y}$, et al: Expression and prognostic roles of PABPC1 in esophageal cancer: correlation with tumor progression and postoperative survival. Oncol Rep 15: 667-671, 2006.

19. Ando T, Ishiguro H, Kimura M, et al: Decreased expression of NDRG1 is correlated with tumor progression and poor prognosis in patients with esophageal squamous cell carcinoma. Dis Esophagus 19: 454-458, 2006. 